\title{
Modelling the recommendation technique for achieving awareness in serious game for obesity
}

\author{
Muhammad Syafiq Bin Mohd Omar, Marina Ismail, Norizan Mat Diah, Suzana Ahmad, Hayati \\ Abd Rahman \\ Faculty of Computer \& Mathematical Sciences, Universiti Teknologi MARA (UiTM), Shah Alam, Malaysia
}

\begin{tabular}{l}
\hline \hline Article Info \\
\hline Article history: \\
Received Apr 30, 2019 \\
Revised Jun 10, 2019 \\
Accepted Jul 2, 2019 \\
\hline
\end{tabular}

Keywords:

Behaviors

Habits

Obesity awareness

Recommendation techniques

Serious game

\begin{abstract}
Obesity among children is increasing alarmingly. Therefore it is crucial to instill the awareness about the danger of being obese to the children. To instill the awareness is a challenge. A good approach is required for the message to be accepted and conceptualized by the children. Serious game has been an important mechanism to assist the achievement of many serious purposes other than for entertainment and enjoyment. This paper proposes the implementation of content-based recommendation technique in serious game for obesity awareness among children. Several recommendation techniques for awareness had been studied and the content-based recommendation technique is found to be suitable to be implemented in games. The game was developed according to game development approach and fulfilled the game characteristics. For this preliminary study, 10 children participated in the experiment to determine the effectiveness of the game. The participants were given a pre-and post test to answer before and after playing the game. The result of the test shows that participants achieved the obesity awareness after playing the game. The content-based recommendation technique is applicable to be adopted in serious games to instill awareness in the players.
\end{abstract}

Copyright $\odot 2019$ Institute of Advanced Engineering and Science. All rights reserved.

\section{Corresponding Author:}

Muhammad Syafiq Bin Mohd Omar,

Faculty of Computer \& Mathematical Sciences,

Universiti Teknologi MARA, Shah Alam, Malaysia.

Email: syafiq982@gmail.com

\section{INTRODUCTION}

In recent years, the design and implementation of video games are growing rapidly not only for entertainment, but also for other serious purposes, one of it is for obesity awareness. This type of games commonly known as serious games, persuasive games as well as gamified interactions, in which they have the ability to change the attitudes, behaviors and habits of the player and allow players to experience situations that are impossible in the real world for safety reasons, cost and time [1-3]. The previous study proved that, playing games can be particular for training and education of such complex systems [4]. In addition, users can also get better explanation and build problem-solving skills by using animations, graphics and interactive environment [5]. Serious games can provide players with enjoyable experience in safe situation at reasonable cost in which those experience can be useful to be applied in real life situation [6].

Nowadays, obesity has become a major health problem with an increased in numbers in all age groups. Obesity is also associated with many medical conditions, including cardiovascular disease and type 2 diabetes [7-9]. In addition, obesity also leads to hypertension. Obesity problem not only involved with an adults, but also children. The reason behind this is because unbalance energy intake and expenditure, with an increase in positive energy balance associated with lifestyle and dietary intake preferences [10]. The current solution for obesity treatment includes eating patterns for weight loss, pharmacotherapy for obesity and physical activity [7, 11]. Besides, current solution for childhood obesity includes providing nutritional 
education to parents and children, monitoring weight and height of children and also providing nutritional counseling to emphasis on daily physical activity [12]. However, these regimes require full commitment from oneself. And commitment may come when the person is fully aware of the importance to stay healthy and do not become obese. Therefore, the authors believe that in order to overcome the above issues, serious game that is embedded with recommendation knowledge can create obesity awareness effectively. This paper investigated recommendation techniques that include content-based recommendation technique, collaborative (social) filtering technique, hybrid recommendation technique and machine learning technique that is responsible in generating feedbacks and recommendation during gameplay that will create obesity awareness and proposed the relevant technique for serious games.

The rest of the paper is structured as follows: Section 2 describes literature review regarding serious games and recommendation technique, Section 3 presents the proposed serious games with application of recommendation technique and Section 4 concludes the discussion.

\section{LITERATURE REVIEW}

\subsection{Serious games}

Serious game is a game that served not only for entertainment purposes, but also for serious purposes such as learning and to create awareness. There are relationship between serious games, video games and serious gaming. Basically, serious games is any piece of software that merges a non-entertaining purpose (serious) with a video game structure (game), while video games is a software that featuring only a "game" dimension, in which video game structure [13]. In addition, serious gaming refers to any video game used for "serious" purposes, whether the "serious" dimension is or is not designed within the software [13].

However, video games can also perform "serious" purposes in which through software modification, "mods" process (convert from video games to serious gaming). For example, when teacher uses entertainment video games during teaching process, and during play session of the games, they create their own "serious scenarios". So, this "serious" dimension is not directly embedded in the game, but the teachers use it to influence the way his or her students might play. Therefore, this process is called "purpose-shifted" [13]. Figure 1 illustrated the relationship between video games, serious games and serious gaming.

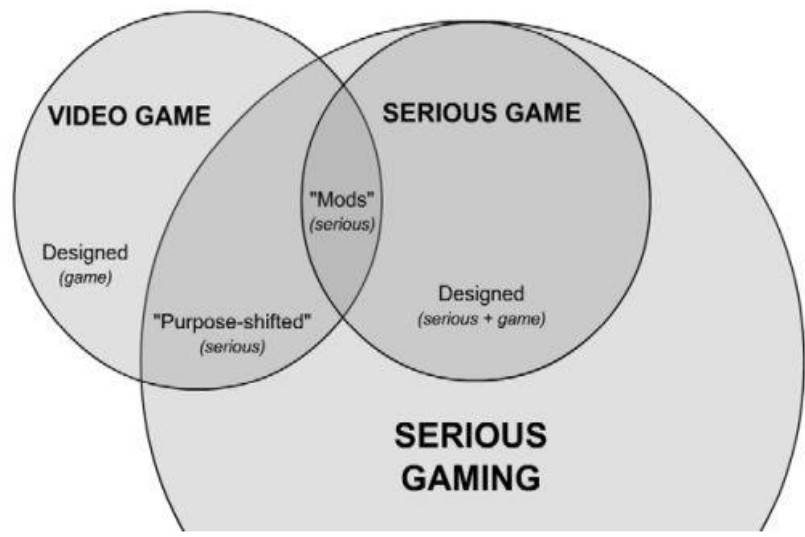

Figure 1. The relationship between video game, serious game and serious gaming [13]

Serious games can also be classified based on Gameplay, Purpose and Scope (GPS) model that combine the analysis of both "serious" and "game" dimensions. Gameplay refers to the type of gameplay used, that is intended to provide information about the game structure of serious games such as how the game should be played [12]. There are two categories of serious games that can relate with Gameplay model in which "Game-based" or "Play-based". For example, Tamagotchi [14] is "play-based" type of game whereas Pac-Man [15] is a "game-based". The difference between these two games is that Tamagotchi don't have sufficient rule rule in defining the goals, in which it cannot be won or lost, whereas Pac-Man incorporating the goals, for example - eating all the pills and avoid the ghosts to win. Therefore, a video game that lacking with goal will be considered as "Play-based", whereas a video game that incorporating with goal will be considered as "Game-based" [13].

Next, the purpose model is the field for which the game is designed, that includes State and Government, Military and Defense, Healthcare, Education, Corporate, Religious, Culture and Art, Ecology, 
Politics, Humanitarian and Advertising [13]. There are existing serious games available for obesity awareness $[16,17]$. These games educate children about good eating habits but did not provide suggestion or recommendation while playing the game. The games focus on rewarding and penalizing the player for a correct and wrong answer through adding and subtracting points from the player. It represents the characteristic of mere video game. However, player was not being informed of the mistakes for them to improve their perspective on eating habits.

\subsection{Achieving awareness}

Awareness is one of an important element in this work. There are many researches that had been done in awareness. The existing work claimed that, awareness can be achieved through situation for which the human will experienced, in which known as situation awareness where interactions between human and environment is very important especially in determining meaning and reflects an increased appreciation for the intimate coupling between perception, decision and action of human [18, 19]. Basically, situation awareness is formally defined as the perception of the elements in the environment within a volume of time and space, the comprehension of their meaning and the projection of their status in the near future [19]. Situation awareness involved three levels. Level 1 is perceiving critical factors in the environment, Level 2 is the understanding of what those factors mean, particularly when integrated together in relation to the person`s goals, and finally in Level 3 is the understanding on what will happen in the future. Figure 2 presented the model of situation awareness in dynamic decision making.

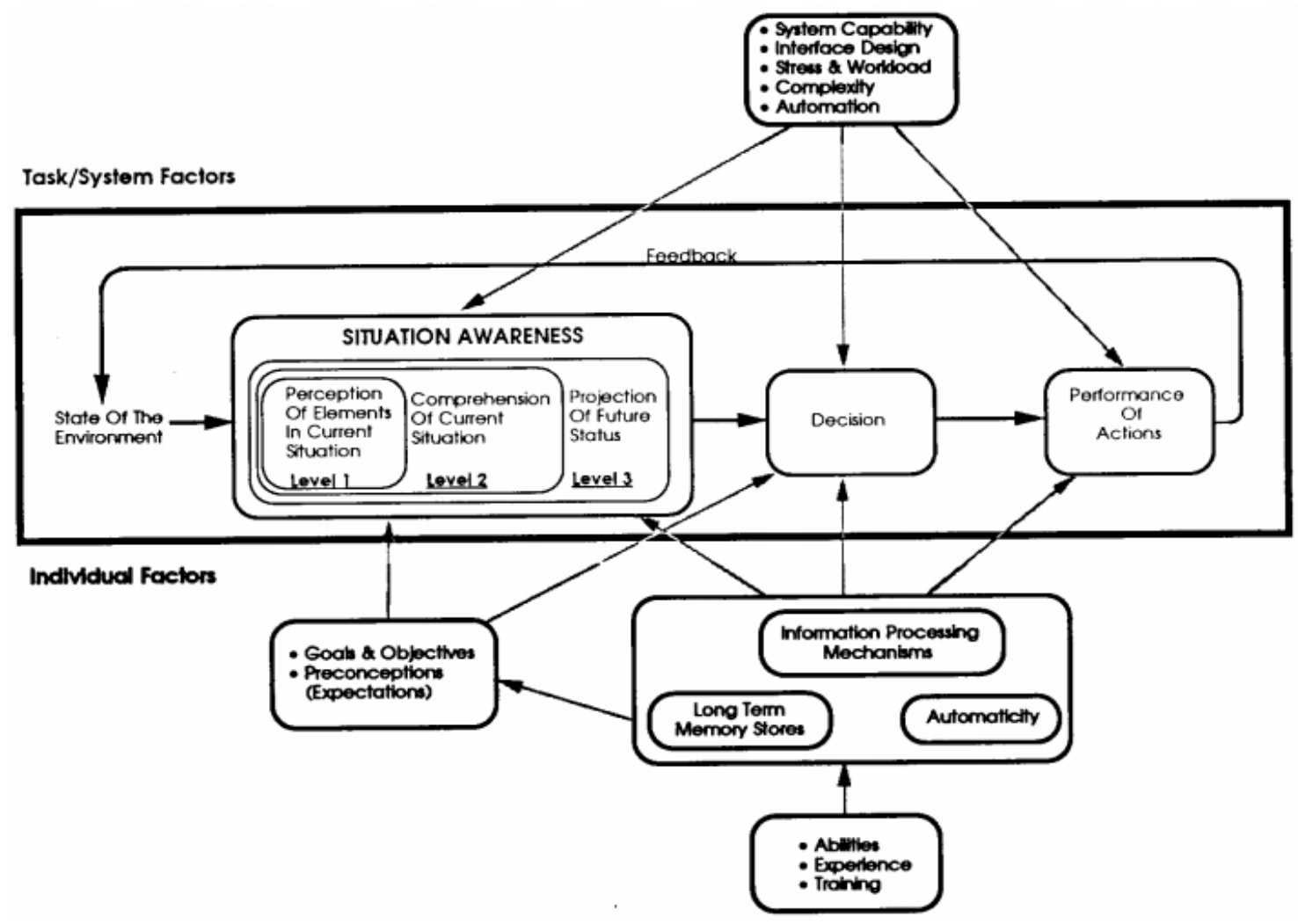

Figure 2. Model of situation awareness [20]

Besides that, awareness in term of psychological and behavior is the set of shifting feature of mindfulness involves decentering from thoughts, emotions, and sensations into a metacognitive state of awareness [21]. This mental operation may be a key link between appraisal and reappraisal, involving a shift in attention from the contents of consciousness to the process of consciousness itself. Through decentering, mindfulness is thought to lead to dis-identification from thoughts and emotions, liberating awareness from schematized narratives about self and world, and promoting flexible selection of adaptive responses [21].

Therefore, to create awareness to the players, situation awareness model can be embedded to the game elements and also game scenarios. In addition, the game elements and game scenarios should be 
influencing the emotion, attention, appraisal, meaning and sensation, so that the awareness can be achieved effectively. Hence, the technique to output the game elements is required. The next section will discuss recommendation techniques that can be implemented in this work in order to create the awareness in a serious game.

\subsection{Recommendation techniques}

Recommendation technique is responsible to suggest games elements, activities and also persuasive strategies to the users [22]. There are many types of recommendation technique that can be used to give knowledge and feedback information along with suggestion of game elements to the users that can increase awareness based on the type of game. An example of recommendation technique includes content-based recommendation technique, collaborative (social) filtering technique, hybrid recommendation technique, context-aware recommendation technique and machine-learning technique [22].

Content-based technique is an algorithm that can be used to recommend similar items to those liked by the user in the past. It generates prediction based on what user preferred in the past. Meanwhile collaborative filtering is used to recommend items that are also liked by similar users. It makes recommendation by finding correlation among users. Hybrid recommendation technique combines multiple techniques for the solution of problems. The combinations of algorithms give a better recommendation as compared to using a single algorithm. In context-aware recommendation technique, this technique will consider the context in which the recommendation occurs. Machine learning technique can be used to learn about users, and predict the suitable elements to be output to users. To the best of our knowledge, there is little work that had been done to implement recommendation technique for serious games that can create awareness in which serious games to create awareness about community policing [17].

The existing work had been done by developing serious game model for cultural heritage [23]. In this work, statistical ontology-based algorithm were used to build the textures of 3D model. Next, there also existing work on the application of k-Nearest Neighbor (k-NN) algorithm for gesture classification [24]. Besides that, there also existing work on developing serious game for promoting green transportation [25]. Basically, transportation mode recognition and machine learning technique is used to provide bonuses and penalties to the users based on their daily choices type of transportation. In this work, transport detection algorithm were used to enable a feedback from real-life actions into the game [25].

There also most recent existing work that had been done for developing serious games to create awareness about community policing that known as TRILLION [17]. TRILLION is implemented with collaborative filtering technique for their client-server model. The client runs on mobile personal devices for the computational part, while the server side provides data regarding the game`s list and data model linked to the game such as items, characters, events and actions. In addition, there is also a community element in TRILLION. This will enable the engagement and the collaboration of players. The purpose is to stimulate discussion around the themes of the project and to enhance citizens relationship, especially for convincing the important of community policing [17]. This is the part where collaborative filtering algorithm plays it roles to create awareness about the importance of community policing to the players. The results of this study found that, the game have a positive impact to create awareness about community policing [17].

Based on literature review, most serious games were developed as play-based for the training purposes in the scope of healthcare. In addition, there is also little work that had been done to use recommendation technique for awareness purposes. The most similar work is the use of collaborative-filtering algorithm in TRILLIONS game [17]. However, this is an online game which requires collaboration from the player community. Hence, this work will extend the existing work in terms of serious game methodology, in which the recommendation is being used to give knowledge for awareness through the gameplay.

\section{RESEARCH METHOD}

On the earlier discussion of the serious game and recommendation technique, it was found that awareness games require some recommendation technique to persuade the player into changing of behavior or habit. We are proposing the inclusion of content based recommendation technique for this obesity awareness game.

The modifications will be done on the design components, in which game scenarios and game items will be the platform for recommendation of knowledge within the game. Figure 3 illustrated the extension for the game design components. 


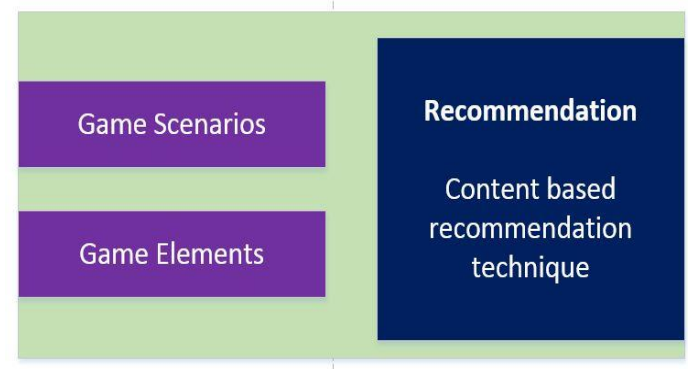

Figure 3. Modification on game design component

The game scenarios are represented by the gaming scene and its environment. Within the scenarios are game elements that encompasses of multiple elements such as motivational, interactive, fun and multimedia. The motivational elements are designed with the incorporation of animated characters telling about the obesity and invite the players to fight the obesity through knowledge. Interactivity is created through the interactivity within the game; where the player is required to move around to collect the good food and avoid the unhealthy food. Fun is the challenges that are created within the gameplay. Player needs to collect the good food and avoid the unhealthy food within the stipulated time or score will be deducted. This creates the game challenge and fun for the game. Multimedia elements are designed through the use of animated character and intriguing sound.

In order to instill the awareness for the player, besides giving the introductory messages, the content based recommendation technique is implemented through the recommendation messages. These messages will pop-up when the player makes a mistake by collecting the unhealthy food. These messages will inform the player of the mistake that they have done and make them aware of the wrong choice that they have made. These messages will eventually instill the knowledge of good and unhealthy food and the consequences of being obese. Table 1 summarizes the game elements for serious games with recommendation technique.

Table 1. Game elements for serious game with recommendation technique

\begin{tabular}{|c|c|c|}
\hline Game element & Description & Attributes \\
\hline Motivational elements (usefulness) & $\begin{array}{l}\text { Ability in affecting player`s thought, actions } \\
\text { and reactions regarding meaningful gameplay } \\
\text { and learning }\end{array}$ & $\begin{array}{l}\text { The reward and challenge in the game } \\
\text { through the scoring system. }\end{array}$ \\
\hline Interactive elements (Interactivity) & $\begin{array}{l}\text { Provide the opportunities for participation and } \\
\text { involvement in gaming activities. }\end{array}$ & $\begin{array}{l}\text { The movement of game's character in } \\
\text { order to collect the good food. }\end{array}$ \\
\hline Fun elements (Playfulness) & $\begin{array}{l}\text { Elements that trigger player's sense of } \\
\text { enjoyment and excitement. }\end{array}$ & $\begin{array}{l}\text { The challenges to avoid colliding with } \\
\text { the unhealthy food will increase } \\
\text { playfulness. }\end{array}$ \\
\hline $\begin{array}{l}\text { Multimedia elements } \\
\text { (Attractiveness) }\end{array}$ & To attract player`s attention. & $\begin{array}{l}\text { The use of animated } 2 \mathrm{D} \text { cartoon, } \\
\text { together with the fun audio. }\end{array}$ \\
\hline Recommendation technique & Content based recommendation technique & $\begin{array}{l}\text { Recommendation messages are being } \\
\text { introduced within the game to give } \\
\text { information about the good and } \\
\text { unhealthy food also on the consequence } \\
\text { of being obese. }\end{array}$ \\
\hline
\end{tabular}

The game was tested for its effectiveness with 10 school children whom were randomly chosen. The experiment design was using the pre-and post test. The results of the pre and post test were compared to measure the level of awareness on good food and obesity among the children. The pre-and post-test results show that participants achived the obesity awareness after playing the serious game with recommendation technique.

\section{CONCLUSION}

Based on the study it can be concluded that serious game with recommendation technique can give the knowledge about obesity to the chidren during gameplay. The use of content based recommendation technique to create awareness on obesity is applied through the recommendation messages that inform the player about the healthy and unhealthy food as well as the consequences of being obese. Through the knowledge that had been given during gameplay, the children can achieve obesity awareness after playing the 
games. The children will always remember the recommendation messages which they are read during the gameplay and able to apply it in their real life.

\section{ACKNOWLEDGEMENTS}

Researcher acknowledge funding support from Universiti Teknologi MARA internal grant BESTARI, grant No. 600-IRMI/PERDANA 5/3 BESTARI (097/2018), and the Research Management Center, UiTM, Shah Alam.

\section{REFERENCES}

[1] Ruppert, B. "New directions in virtual environments and gaming to address obesity and diabetes: Industry perspective". Journal of Diabetes Science Technology. 2011.

[2] Orji, R., Mandryk, R.L. and Vassileva, J. "Improving the efficacy of games for change using personalization models". ACM Transactions on Computer-Human Interaction (TOCHI), 24(5), p.32. 2017.

[3] Busch, M., Mattheiss, E., Orji, R., Marczewski, A., Hochleitner, W., Lankes, M., Nacke, L.E., Tscheligi, M. "Personalization in Serious and Persuasive Games and Gamified Interactions". In Proceedings of the 2015 Annual Symposium on Computer-Human Interaction in Play-CHI PLAY'15 ACM. pp. 811-816. 2015.

[4] Douven, W., Mul, M. L., Son, L., Bakker, N., Radosevich, G., \& Hendriks, A. "Games to create awareness and design policies for transboundary cooperation in river basins: Lessons from the shariva game of the Mekong river commission". Water resources management, 28(5), 1431-1447. 2014.

[5] Deshpande, A. A., \& Huang, S. H. "Simulation games in engineering education: A state-of-the-art review". Computer applications in engineering education, 19(3), 399-410. 2011.

[6] Mokhtar, N., Ismail, A. and Muda, Z. "Preliminary Study: Flood Awareness Training Preparation Using Serious Games". Asia-Pacific Journal of Information Technology and Multimedia, 7(2-2). 2019.

[7] Hassan, M. M., Hossain, M.S., Alamri, A., Hossain, M.A., Al-Qurishi, M., Aldukhayyil, Y. and Ahmed, D. T. "A cloud-based serious games framework for obesity". In Proceedings of the 1st ACM multimedia international workshop on Cloud-based multimedia applications and services for e-health. pp. 15-20. November 2012.

[8] Skinner, A.C., Perrin, E.M. and Skelton, J .A. "Prevalence of obesity and severe obesity in US children, 1999-2014”. Obesity, 24(5), pp.1116-1123. 2016.

[9] Gunstad, J., Paul, R.H., Cohen, R.A., Tate, D.F., Spitznagel, M.B. and Gordon, E., Elevated body mass index is associated with executive dysfunction in otherwise healthy adults. Comprehensive psychiatry, 48(1), pp. 57-61. 2007.

[10] Sahoo, K., Sahoo, B., Choudhury, A.K., Sofi, N.Y., Kumar, R. and Bhadoria, A.S. "Childhood obesity: causes and consequences". Journal of family medicine and primary care, 4(2), p.187. 2015.

[11] Turner, M., Jannah, N., Kahan, S., Gallagher, C. and Dietz, W. "Current knowledge of obesity treatment guidelines by health care professionals". Obesity, 26(4), pp.665-671. 2018.

[12] Pandita, A., Sharma, D., Pandita, D., Pawar, S., Tariq, M. and Kaul, A. "Childhood obesity: prevention is better than cure". Diabetes, metabolic syndrome and obesity: targets and therapy, 9, p.83. 2016.

[13] Djaouti, D., Alvarez, J. and Jessel, J.P. "Classifying serious games: the G/P/S model”. Handbook of research on improving learning and motivation through educational games: Multidisciplinary approaches, 2, pp.118-136. 2011.

[14] S. H. A. Hamid and N. Ismail, "The Design of MobiGP by Using Tamagotchi," 2007 First IEEE International Symposium on Information Technologies and Applications in Education, Kunming, 2007, pp. 382-387.

[15] G. Foderaro, A. Swingler and S. Ferrari, "A Model-Based Approach to OptimizingMs. Pac-ManGame Strategies in Real Time," in IEEE Transactions on Computational Intelligence and AI in Games, vol. 9, no. 2, pp. 153-165, June 2017.

[16] R. Baranyi, B. Steyrer, L. Lechner, G. N. Agbektas, N. Lederer and T. Grechenig, "NutritionRush-a serious game to support people with the awareness of their nutrition intake," 2017 IEEE 5th International Conference on Serious Games and Applications for Health (SeGAH), Perth, WA, 2017, pp. 1-8.

[17] Sorace, S., Quercia, E., La Mattina, E., Patrikakis, C.Z., Bacon, L., Loukas, G. and Mackinnon, L., "Serious Games: An Attractive Approach to Improve Awareness". Community-Oriented Policing and Technological Innovations, pp.1-9. 2018.

[18] Flach, J. M. "Situation awareness: Proceed with caution". Human factors, 37(1), pp.149-157. 1995.

[19] Endsley, M. R. "Automation and situation awareness". In Automation and human performance. Routledge. pp. 183-202. 2018.

[20] Endsley, M. R. "Situation awareness misconceptions and misunderstandings". Journal of Cognitive Engineering and Decision Making, 9(1), pp.4-32. 2015.

[21] Garland, E.L., Farb, N.A., R. Goldin, P. and Fredrickson, B.L. "Mindfulness broadens awareness and builds eudaimonic meaning: A process model of mindful positive emotion regulation". Psychological Inquiry, 26(4), pp.293-314.

[22] Tondello, G.F., Orji, R. and Nacke, L.E. "Recommender Systems for Personalized Gamification". In Adjunct Publication of the 25th Conference on User Modelling, Adaptation and Personalization ACM. pp. 425-430. 2017 July.

[23] Bellotti, F., Berta, R., De Gloria, A., D'ursi, A. and Fiore, V. "A serious game model for cultural heritage". Journal on Computing and Cultural Heritage (JOCCH), 5(4), p.17. 2012. 
[24] Chae, J.H., Lim, J. H. and Lee, J.J. "Gesture Classification Based on k-Nearest Neighbors Algorithm for Game Interface". Journal of Korea Multimedia Society, 19(5), pp.874-880. 2016.

[25] Hedemalm, E., Hallberg, J., Kor, A.L., Andersson, K. and Pattinson, C. "Promoting green transportation via persuasive games". In International conference on Sustainable, Ecological Engineering Design for Society (SEEDS), Leeds, 13-14 September 2017.

\section{BIOGRAPHIES OF AUTHORS}

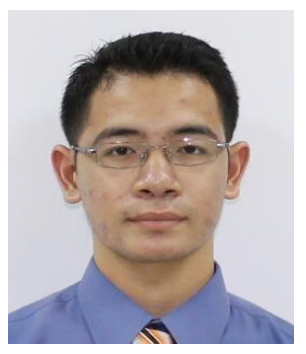

Muhammad Syafiq Bin Mohd Omar received the B.S in Computer Science majoring in Artificial Intelligence from USM, Penang (2017) and M.S in Computer Science from UiTM, Shah Alam (2019). His main research interest are more towards the development of games for education. Besides, his other research interest includes virtual reality development.

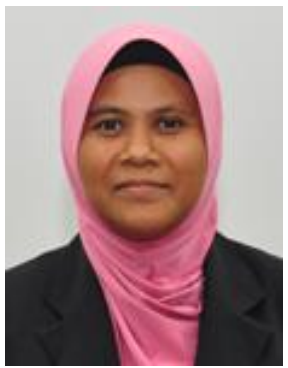

Marina Ismail is an active researcher since 2009. She earned a PhD in Information Science in 2009 from Universiti Kebangsaan Malaysia, a Masters in Computer Science in 2001 from Universiti Putra Malaysia and a Bachelor in Computer Science in 1993 from Universiti Kebangsaan Malaysia. Her research interests are in gamification, content research for assistive applications and emotion learning.

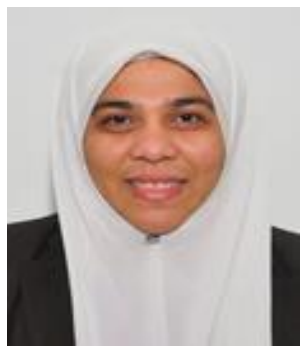

Norizan Mat Diah is an active researcher since 2005. She earned a PhD in Information Science in 2016 from Universiti Kebangsaan Malaysia, a Master in Information Technology (Information Sciences) in 2002 from Universiti Kebangsaan Malaysia and a Bachelor in Computer Science in 1998 from Universiti Universiti Putra Malaysia. Her research interests are in gamification (Game Engine, Game Theory, E-sport), real time feeback (gaming, education, industrial) and Image processing (hand writing, image)

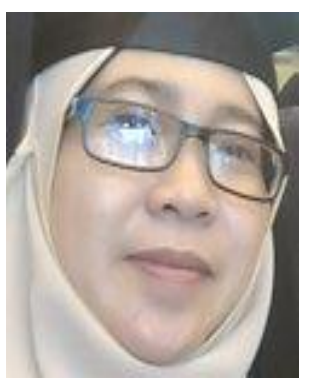

Suzana Ahmad is a Senior Lecturer in the Department of Computer Science at Universiti Teknologi MARA, where she has been since 2001. Her research interest spans both computer education and collaborative works throughout her working years.

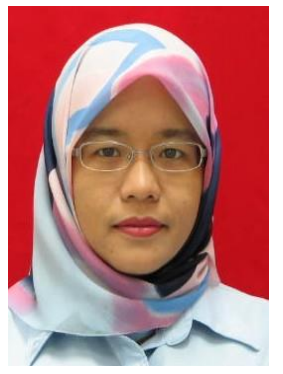

Hayati Abd Rahman (Dr.) is a PhD holder in Information Science at Universiti Kebangsaan Malaysia (UKM), Bangi. She is currently a senior lecturer at Universiti Teknologi MARA (UiTM), Shah Alam, Malaysia. Her area of interest is in Information Retrieval, Semantic and Linguistic Computing and Multimedia. 